\title{
Se fue Hugo, se fue un Maestro
}

Se fue Hugo y su semblanza podría tener múltiples abordajes. Pero en este, que pretende ser un recuerdo afectuoso y agradecido, lo haré desde aquel que nos marcara para siempre: Hugo fue un Maestro de la medicina y así merece ser recordado.

A fines de los años 70 un grupo de jóvenes comenzábamos a transitar nuestro camino en la medicina cardiovascular, el que se iniciaba en una mesa con electrocardiogramas para informar, cuando una mañana llegó a la misma un docente, el que con tono agrio preguntó: "Quién es..., porque dejó un rastro sangriento".

Ese era Hugo Senra, y estaba muy molesto porque el profesor lo había llamado para reprocharle acerca del ECG de un paciente con bloqueo completo de rama izquierda que había sido informado como infarto agudo de miocardio (IAM). Dado el entusiasmo por hacer nuestras primeras armas en interpretar trazados, el informe erróneo de un inexperiente

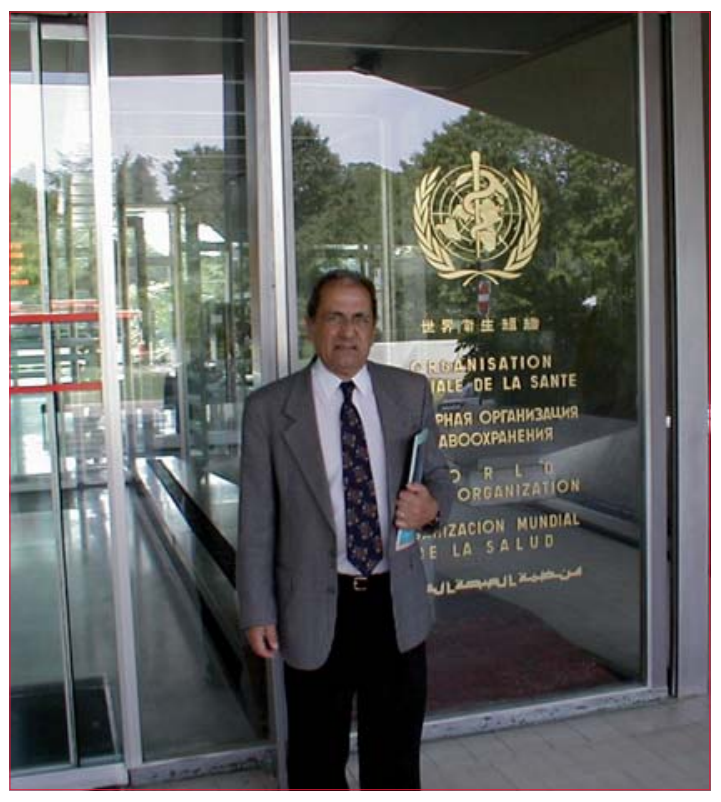
compañero de posgrado y sus consecuencias, se asocian a mi primer recuerdo de Hugo.

Estaba integrado en la Cátedra desde hacía poco tiempo, luego de haber regresado de la residencia en el Instituto Ignacio Chávez de México, una institución líder en el área cardiovascular en aquel entonces.

Hugo nos mostraba una forma diferente de medicina cardiovascular de la que se practicaba en aquel entonces en Uruguay. Nos permitía avizorar que se había producido un cambio importante en los centros de referencia del mundo, que distaba del enfoque tradicional que aún primaba en Uruguay de fines de los años 70, muy anclado en la vieja escuela francesa (la que en Francia, por otra parte, ya había evolucionado).

Junto a un grupo de alumnos de posgrado y algún amigo, se planteó la desafiante empresa de instalar una unidad de cuidados coronarios, algo que en nuestro medio no existía, pues en ese momento el cuidado de los pacientes cardiovasculares agudos estaba en manos de los médicos intensivistas. Hugo estaba convencido de que el manejo agudo del paciente cardiovascular sería más adecuado si lo realizaba un cardiólogo entrenado en ello, lo que posteriormente podríamos comprobar.

Para ello, Hugo conformó un equipo junto a Miguel Benedikt (fallecido recientemente), Joaquín Cobas, Nelson Marino, Eduardo Pajean y J. Alberto Rucks, al que posteriormente sería invitado a integrarme. Ahí comenzaría un largo proceso que desembocaría en UCIP (sigla sugerida por un destacado publicista amigo de Alberto y paciente de Hugo). A partir de la sigla se conformó la expresión Unidad Cardiológica Integral y Preventiva.

Mediante un convenio con el Hospital Español, se consiguió una vieja sala donde se instalaría la unidad. Pero para ello hubo que remodelarla, comenzando por construir una planchada para dividirla en dos, dado que la misma tenía una altura cercana a los 6 metros. Un oficial albañil estaría a cargo de la obra y con Miguel asumimos la tarea de tender la cañería plástica de la futura instalación eléctrica sobre la madera del encofrado, la que luego quedaría cubierta por el hormigón. Posteriormente, Alberto se integraría al grupo de los que nos tocó enhebrar los cables de la electricidad. Estas, junto a muchas otras tareas desarrolladas durante el proceso de construcción como consecuencia de la escasez de fondos, ilustra acerca del compromiso y la dedicación de aquel grupo de jóvenes para llevar adelante su proyecto, liderados por la visión e impulso de Hugo.

Una vez instalados, en marzo de 1981, comenzamos a manejar estos pacientes bajo su rigurosa tutela. 
Inicialmente cada guardia era un sufrimiento, pues cuando creíamos que habíamos hecho todo bien, llegaba Hugo y nos marcaba algo que habíamos omitido o equivocado. Y, parafraseando a uno de sus maestros mexicanos, decía "seguro que lo mejor del ECG está en la papelera", aludiendo a que la selección que hacíamos de las tiras para pegar en la historia a veces no incluía los aspectos clave del trazado.

Así, en el día a día al lado del paciente, nos enseñó la necesidad de ser rigurosos en su examen, en el análisis de sus estudios paraclínicos y en la necesidad de considerar sus preferencias para tomar decisiones.

Durante un período las guardias de 24 horas las realizábamos entre dos de los fundadores, luego, una camada de colegas más jóvenes se uniría al equipo: Aníbal Alamón, Eduardo Bianco, Daniel Guzzo, Mario Lado, Ricardo Lorenzo, Ricardo Lluberas, Roberto Oromí, O. Raúl Pereira, Bernardo Pérez, John Torres, Horacio Vázquez (dolorosamente desaparecido cuando aún tenía mucho por dar) y Mario Zelarayán, a quienes más tarde se unirían Eduardo Benkel y Roberto Paganini (prematuramente desaparecido en un accidente de tránsito). Hubo muchos más jóvenes colegas, que en aquel momento cursaban posgrados de cardiología o de otras especialidades, y colegas en ejercicio, que hacían pasantías por UCIP de mayor o menor duración, que también tuvieron oportunidad de aprender a su lado en el clima fermental de la unidad.

Es que Hugo imponía una forma de trabajo exigente y rigurosa, incorporando al cuidado elementos que en aquel momento recién se introducían en nuestro medio, y de los que él traía su experiencia mexicana, integrándolos al cuidado con marcada racionalidad. Así, mucha gente valiosa, llamada luego a ocupar lugares destacados en la medicina cardiovascular de nuestro país, tanto en Montevideo como en el interior, acudió a UCIP porque percibió que allí se estaba gestando una nueva forma de practicar la medicina cardiovascular.

En esa época eran raras las historias clínicas que, además de la descripción de signos y síntomas, planteasen el diagnóstico presuntivo o definitivo del paciente. Con Hugo aprendimos que si una historia clínica no tenía planteado el diagnóstico, sus posibles alternativas y el curso posterior a seguir, no nos la iba a admitir. Esto que puede parecer elemental, rara vez sucedía en nuestro medio, y el incorporar sus recomendaciones al quehacer diario nos permitió a muchos crecer en la profesión.

En la primavera de 1983 con Hugo, Joaquín y Miguel concurrimos al Congreso de la Cardiología Argentina, realizado por la FAC y la SAC de manera conjunta en la ciudad de San Miguel de Tucumán. Allí, escucharíamos a William Ganz relatar su experiencia en trombolisis intravenosa en el IAM, entre tantas otras cosas presentadas en ese congreso de gran envergadura, las que a mi juicio también eran muy interesantes. Pero Hugo comprendió rápidamente que lo más relevante era la trombolisis, y que el camino para el manejo del infarto de miocardio en su etapa aguda era ese, y comenzó a trabajar con insistencia y perseverancia para poder implementarlo. En primer lugar, debió convencer al gerente del Laboratorio Hoechst para que trajese la estreptoquinasa a Uruguay, pues en ese momento no se disponía de ella. Le llevó tiempo convencerlo, pues el fármaco no se usaba en el país y la empresa creía que no se vendería, por lo que no estaba interesado en tomar el riesgo. Luego organizó la visita de Ganz a Uruguay, donde este presentaría su protocolo de trombolíticos en el IAM, quedando de esa manera todo pronto para comenzar la trombolisis.

Así, a fines de 1983 en un llamado en la UCM, asistí al padre de una colega que presentaba un IAM inferior, al que trasladé al área de cuidados intensivos generales y posoperatorio de cirugía cardíaca en la Asociación Española (la que en ese momento ocupaba una planta física vecina), donde Hugo, junto a Walter Verderosa (director del CTI), administraron estreptoquinasa con el protocolo de Ganz al primer paciente. A esto seguiría una amplia serie de casos tratados en UCIP y en la Española, donde Hugo había llevado a sus jóvenes alumnos como parte del equipo de posoperatorio de cirugía cardíaca.

El sábado era el día de ateneo en UCIP, y allí, además del intercambio clínico, comenzó a aflorar lo que luego se daría en llamar Medicina basada en evidencia. Recuerdo que en un ateneo alguien apareció con una publicación titulada ... Overview of results on mortality... from 33 randomized controlled trials (así se denominaba lo que posteriormente sería llamado revisión sistemática y metaanálisis) publicada en el European Journal of Cardiology. Y ello nos llenó de asombro, porque no entendíamos de qué se trataba. Y claro, nosotros no sabíamos que era necesaria evidencia válida que mostrase el beneficio del tratamiento trombolítico, pues estábamos convencidos, con Hugo a la cabeza, de que era efectivo, pues usualmente luego de administrado los pacientes dejaban de tener dolor y el ST se renivelaba rápidamente. No habíamos salido aún de la etapa en que se decidía si un tratamiento era efectivo o no en base a la experiencia personal en su empleo.

Poco o nada sabíamos de los ensayos clínicos randomizados y mucho menos de lo que era un metaanálisis. El metaanálisis que no pudimos entender a cabalidad ese sábado, era el que planteaba en 1985 que la trombolisis en el IAM reducía la mortalidad, algo que luego sería confirmado por los dos megaestudios: GISSI (1986) e ISIS-2 (1988).

En aquella época, a instancias de Enrique Besada, se desarrollaría el que se denominó Estudio Multi- 
céntrico de Estreptoquinasa en el IAM (EMUFI), lo que vendría a ser la primera iniciativa multicéntrica en nuestro país. La visión de Enrique, de tomar lo que se hacía bien en muy pocos lugares y tratar de extenderlo a todo el país fue clave, pues ello permitió que pacientes de todo el Uruguay se beneficiasen con ese tratamiento. Fue una experiencia adelantada de lo que muchos años después la American Heart Association promoviese mediante su programa Get with the Guidelines.

A ello seguiría la participación en EMERAS, el primer estudio de investigación multicéntrico en la región, y cuyos resultados se presentaron en el congreso del American College de 1991, al que concurrimos quienes habíamos trabajado en el proyecto. En esa oportunidad, una vez terminado el congreso, con Hugo nos dirigimos al Instituto Ignacio Chávez, donde habíamos sido invitados a presentar esos mismos resultados. Pude palpar de primera mano el aprecio que los colegas del mismo sentían por Hugo.

El ciclo de UCIP un día se cerraría y eso generó en todos mucha tristeza y una sensación de pérdida irreparable. Como dijo en aquel momento Nelson, el que en UCIP siempre tenía una frase justa, "mientras duró, fue bueno". Claro que procesar que ese lugar que había cambiado nuestras vidas profesionales se había terminado, costó mucho y fue doloroso. Al final comprendimos, como dijera Nelson, que había sido tan bueno que a un gran número de colegas hizo concebir la práctica de la medicina de una manera diferente, lo que seguramente contribuyó a mejorar los cuidados en el área de la salud cardiovascular.

Posteriormente la vida nos daría la oportunidad de trabajar junto a Hugo en la policlínica de la Asociación Española, donde compartimos pacientes, sueños y proyectos. Los ateneos promovidos por Hugo durante muchos años continuaron siendo faro de atracción para muchos colegas.

$\mathrm{Al}$ hacer balance del largo camino recorrido junto a Hugo las palabras afloran solas: muchas gracias Maestro por la impronta que dejaste en tus muchos alumnos y por tu contribución invalorable a una mejor medicina cardiovascular para nuestro país. 